\title{
Sociodemographic determinants of perceived influences on food choice in a nationally representative sample of Irish adults
}

\author{
M Kearney ${ }^{1, *}$, JM Kearney ${ }^{1}$, A Dunne ${ }^{2}$ and MJ Gibney ${ }^{1}$ \\ 'Institute of European Food Studies, Trinity College, Dublin 2, Ireland: \\ ${ }^{2}$ Department of Statistics, University College Dublin, Belfield, Dublin 4, Ireland \\ Submitted 18 April 1999: Accepted 1 September 1999
}

\begin{abstract}
Objective: To identify the most important motivations for food choice from the point of view of the consumer in the Irish population, and to characterize those subjects who do and do not regard nutrition as a significant consideration in food choice. Design: As part of a pan-European Union (EU) survey on consumer attitudes to food, nutrition and health, a quota-controlled, nationally representative sample of Irish adults $(n=1009)$ aged 15 years upwards, completed an interview-assisted, closeended questionnaire. Subjects selected three factors, from a list of 15, which they believed had the greatest influence on their food choice.

Setting: The interviews for the survey were conducted in subjects' homes.

Results: 'Quality/freshness of food' was the most frequently selected food choice factor (51\%) followed by 'taste' (43\%) and 'trying to eat a healthy diet' (36\%). Female gender, increasing age and higher levels of education were found to be independent sociodemographic factors affecting the selection of 'trying to eat a healthy diet' as an important factor in food choice.

Conclusions: Although included in the top five most frequently selected factors affecting food choice, nutrition/healthy eating does not appear to have top priority for the majority of Irish adults. There are differences between the various sociodemographic groups within the population; males and younger subjects appear to require specific nutrition promotion messages.
\end{abstract}

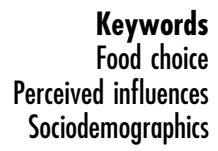

Keywords

Perceived influences Sociodemographics
It is gradually being accepted that understanding personal and socioeconomic predictors of nutrition behaviour and dietary change is necessary for the development of effective public health nutrition education programmes ${ }^{1,2}$. In this respect it would be important to examine motivations for food choice prevalent among the general population. What people buy and eat depends not only on individual factors, but also on social, cultural, economic and environmental factors, all of which are interrelated ${ }^{3}$.

In a review of factors affecting food choice, it has been recommended that research is conducted on what cultural factors affect food choice and to develop an understanding of what food and food choice really mean to the consumer ${ }^{4}$. Harnack et al. have reviewed the literature on environmental and social factors affecting dietary behaviour for chronic disease prevention in American populations ${ }^{5}$. According to them, taste preferences appear to consistently represent a barrier to healthier eating as well as cost and confusion about dietary guidelines. However, it is probable that data from USA populations are not especially relevant for European adults and there is also the question whether the above results apply only to specific dietary measures for disease prevention, rather than to general food choice. A 'healthy' attitude to eating is regarded as an ideal to be striven for in nutrition education ${ }^{6}-$ that is it would not be considered 'healthy' for everyone in the population to be continuously making food choices out of fear of chronic disease.

The Institute of European Food Studies (IEFS), based in Dublin, has conducted a pan-EU survey on consumer attitudes to food, nutrition and health ${ }^{7}$, affording the opportunity to look at nutrition attitudes of nationally representative samples of adults in 15 European countries. One of the aims of the IEFS survey was to identify the relative importance of factors affecting food choice, from the point of view of the consumer $^{8}$. We report here the results from the Irish population and their motivations for food choice.

It has previously been shown that Irish adults believe 'eating a healthy diet' to be the most important factor for the promotion of long-term good health, particularly those subjects with a high level of education? However, as the healthy population are not likely to be highly concerned about their health for the long term in everyday life, it may be more relevant to examine whether the population regard health/nutrition to be 
an important motivator in food choice, a more frequent everyday situation. The objective of the present study was to characterize the people who do and do not regard eating a healthy diet to be an important influence on their choice of food in general, and further to gain an insight into what the Irish population perceive as priorities when choosing food. As nutrition education is more likely to be successful if separate messages are targeted at specific groups in a population, it was also relevant to examine the factors perceived to affect food choice among different demographic groups in the population.

\section{Methods}

The study was conducted as part of the IEFS pan-EU survey on consumer attitudes to food, nutrition and health. The methods have been previously described ${ }^{10}$. Briefly, this survey involved nationally representative samples of approximately 1000 adults from the 15 member states of the EU completing interview-assisted questionnaires on their attitudes towards nutrition and health. Outlined below is a description of the procedures used for questionnaire design, sample selection and statistical analysis, relevant to the Irish sample.

\section{Questionnaire design and development}

An expert panel including nutritionists and food behavioural scientists from the 15 member states of the EU together with market researchers from industrial sponsors of the IEFS defined the specific objectives of the questionnaire, its format and administration. The following topics were dealt with in the questionnaire:

1. Perceived influences on food choice.

2. Consumers' definitions of 'healthy eating' (in their own words).

3. Sources of information on healthy eating and degree of trust in major sources.

4. Perception of need for dietary change, stages of dietary change and qualitative nature of dietary changes attempted/intended.

5. Perceived benefits of and barriers to healthy eating.

The final questionnaire (copies of which are available from the authors) included 13 close-ended questions. The question on consumers' definitions of healthy eating was open-ended. The questionnaire (translated version where necessary) was piloted in 13 member states before administration. In the present paper, the Irish results of the question on perceived influences on food choice are considered. Results on the other topics are reported elsewhere ${ }^{8,11-16}$.
The question on perceived influences on food choice was the first in the questionnaire. Before the question was asked, no prompting was given that the subsequent questions would be on the topic of nutrition and health - this was to avoid the possibility of subjects providing a 'nutritionally desirable' response. Subjects were shown a list of 15 possible factors and asked to select the three (in order of importance) which they thought had the greatest influences on their food choice. The 15 factors were as follows:

- quality/freshness of food;

- habit/routine;

- price of food;

- what my family/spouse will eat;

- trying to eat a healthy/balanced diet;

- taste of food;

- convenience in preparation;

- presentation/packaging;

- slimming;

- vegetarian/special eating habits;

- prescribed diet;

- content of additives/colours/preservatives;

- cultural/religious/ethnic background;

- availability of food;

- someone else decides on most of the food I eat;

- other.

Questions on sociodemographic information were also included to classify the subjects by the following parameters: sex, age, region (Dublin, Leinster, Munster, Connaught/Ulster), education (highest level achieved - primary, secondary, tertiary), social class, employment status (working full/part-time, housewife, still in education, unemployed, retired), marital status, number of people in the household and number of children younger than 15 years in the household. Social class was defined by the occupation of the head of the household, according to the systems commonly used in Ireland and the $\mathrm{UK}^{17}$. Using this system people can be divided into six groups: $\mathrm{AB}$, professional/managerial/ upper middle class; $\mathrm{C} 1$, lower middle class; C2, skilled working class; DE, other working class/low level of subsistence, F1, farmers with farms greater than 50 acres; F2, farmers with farms less than 50 acres.

\section{Sample selection}

Taylor-Nelson AGB (Ireland) Ltd, a market research organization, recruited the sample and conducted the questionnaires as part of an omnibus survey. An omnibus survey is one in which subjects complete questionnaires on separate topics from different clients in a single session. Taylor-Nelson recruits a nationally representative sample of adults $(n=1000)$ every month $(250$ per week). The sampling procedure in the present study conformed to the standards of marketing research ${ }^{18}$. 
Multistage stratified cluster sampling was used, with quotas applied, to ensure national representativeness. The Republic of Ireland was divided into 15 discrete regional and area divisions. Within each area, district electoral divisions were selected (as the sampling units) with a probability proportional to the population size for that area. Sampling points, i.e. the point at where subject selection occurs, were chosen from each sampling unit ${ }^{19}$. A total of 60 sampling points ensured that a representative cross-section of the community was obtained. Within each sampling point, interviewers followed a predesignated random route ${ }^{20}$ to select approximately 16 subjects. Demographic quota controls (age, sex, social class) were imposed on the sample selection to ensure that the sample accurately represented these known characteristics of the population under study, based on the most recent census ${ }^{21,22}$. Only one person per household was interviewed. In cases where more than one member of a household was eligible for selection the 'next birthday' method was used, i.e. the subject whose birthday was closest to the interview date completed the interview.

\section{Questionnaire administration}

The questionnaires were administered using an inhouse, face-to-face interview-assisted technique. The interviewer was instructed not to disclose that the survey was about nutrition or healthy eating and this was important for the interpretation of responses on perceived influences on food choice. Flash cards with the various response options were used to facilitate responses. Care was taken to sequentially reverse the order of options in the questions to eliminate possible bias resulting from subjects selecting the first item in a list. Standard checking procedures of at least $10 \%$ call back in were employed.

Data entry was conducted by Taylor-Nelson AGB (Ireland) Ltd into tab-delimited ASCII files and a format suitable for analysis by SPSS for Windows (version 6.1).

\section{Statistical analysis}

Pearson 'goodness of fit' chi-square statistics were initially used to test the dependence of the selection of a particular factor as an important influence on food choice on each sociodemographic characteristic, as listed above. Factors selected (as the first, second or third most important) by less than $10 \%$ of the sample were not included in this analysis. The Bonferroni adjustment for statistical significance was applied to control for the effects of multiple testing.

Logistic regression modelling was conducted in order to determine whether the sociodemographic characteristics exerted independent effects on the perception that 'healthy eating' was an important influence on food choice. The sample was divided into two groups, those who selected 'healthy eating' in their top three influences on food choice versus those who did not, creating a binary dependent variable. In the logistic regression models, the group who did not select 'healthy eating' as an influence was the reference group. The independent variables were sex, age, education level, social class, employment status, region, marital status, size of household and number of children in the household. Each independent variable was adjusted for each of the other independent variables. In the models, indicator variable coding was used for the contrasts in the independent variables, such that the reference for the categorical variable was 0 . The reference categories were as follows: female, $55+$ years, tertiary level education, social class $\mathrm{AB}$, working, Dublin, single, one-person household and no children. Forward step logistic regression analysis was conducted. The possibility of there being interactions between the main effects in the final model was also assessed.

\section{Results}

A total of 1009 subjects completed the questionnaire in the Republic of Ireland. Because sample selection was by non-probability methods, the calculation of a response rate is not appropriate. The sample was nationally representative ${ }^{21,22}$ and consisted of $49 \%$ men and $51 \%$ women; $43 \%$ were between the ages of 15 and

Table 1 Factors selected by a nationally representative sample of 1009 Irish adults as important influences on food choice

\begin{tabular}{lcccc}
\hline & \multicolumn{3}{c}{ Per cent selecting } \\
\cline { 2 - 4 } & Most important & $\begin{array}{r}\text { Second most } \\
\text { important }\end{array}$ & $\begin{array}{c}\text { Third most } \\
\text { important }\end{array}$ & Total \\
\hline Quality & 25 & 13 & 13 & 51 \\
Taste & 15 & 14 & 14 & 43 \\
Trying to eat a healthy diet & 13 & 14 & 10 & 37 \\
Other people's preferences & 12 & 11 & 11 & 34 \\
Habit & 9 & 12 & 10 & 31 \\
Price & 7 & 13 & 5 & 30 \\
Someone else decides & 8 & 4 & 8 & 17 \\
Availability & 3 & 6 & 6 & 15 \\
Convenience & 2 & & & 14 \\
\hline
\end{tabular}


Table 2 The main factors perceived by 1009 Irish adults to influence their food choice, by demographic characteristics (\%)

\begin{tabular}{|c|c|c|c|c|c|c|c|c|c|}
\hline & Quality & Taste & $\begin{array}{l}\text { Trying to eat } \\
\text { a healthy diet }\end{array}$ & $\begin{array}{c}\text { Other } \\
\text { people's } \\
\text { preferences }\end{array}$ & Habit & Price & $\begin{array}{c}\text { Someone else } \\
\text { decides }\end{array}$ & Availability & Convenience \\
\hline \multicolumn{10}{|l|}{ Sex } \\
\hline Male & 44 & 49 & 27 & 31 & 35 & 27 & 28 & 19 & 15 \\
\hline Female & $\begin{array}{c}56 \\
P=0.00018\end{array}$ & $\begin{array}{c}38 \\
P=0.00037\end{array}$ & $\begin{array}{c}44 \\
P<0.00001\end{array}$ & $\begin{array}{l}37 \\
\text { NS }\end{array}$ & $\begin{array}{l}27 \\
\text { NS }\end{array}$ & $\begin{array}{l}32 \\
\text { NS }\end{array}$ & $\begin{array}{c}7 \\
P<0.00001\end{array}$ & $\begin{array}{c}11 \\
P=0.00072\end{array}$ & $\begin{array}{r}12 \\
\text { NS }\end{array}$ \\
\hline \multicolumn{10}{|l|}{ Age (years) } \\
\hline $15-34$ & 38 & 54 & 30 & 34 & 29 & 29 & 23 & 17 & 16 \\
\hline $35-54$ & 57 & 35 & 38 & 39 & 31 & 30 & 12 & 11 & 12 \\
\hline \multirow[t]{2}{*}{$55+$} & 60 & 35 & 42 & 27 & 34 & 32 & 15 & 15 & 11 \\
\hline & $P<0.0009$ & $P<0.00001$ & $P=0.00546$ & $P=0.00458$ & NS & NS & $P=0.00014$ & NS & NS \\
\hline \multicolumn{10}{|l|}{ Education } \\
\hline $\begin{array}{l}\text { Primary } \\
\text { Secondary }\end{array}$ & $\begin{array}{l}45 \\
52\end{array}$ & $\begin{array}{l}45 \\
42\end{array}$ & $\begin{array}{l}25 \\
35\end{array}$ & $\begin{array}{l}32 \\
36\end{array}$ & $\begin{array}{l}43 \\
28\end{array}$ & $\begin{array}{l}39 \\
28\end{array}$ & 19 & 17 & 12 \\
\hline \multirow{3}{*}{ Tertiary } & 52 & 42 & 35 & 36 & 28 & 28 & 18 & 16 & 12 \\
\hline & 54 & 47 & 58 & 29 & 24 & 21 & 10 & 8 & 21 \\
\hline & NS & NS & $P<0.00001$ & NS & $P=0.00001$ & $P=0.0001$ & NS & NS & NS \\
\hline \multicolumn{10}{|l|}{ Social class } \\
\hline$A B$ & 60 & 44 & 62 & 30 & 19 & 9 & 22 & 12 & 15 \\
\hline C1 & 53 & 48 & 44 & 31 & 26 & 25 & 12 & 15 & 18 \\
\hline $\mathrm{C} 2$ & 54 & 41 & 30 & 35 & 33 & 27 & 18 & 13 & 15 \\
\hline DE & 41 & 45 & 29 & 36 & 33 & 39 & 17 & 17 & 10 \\
\hline F1 & 61 & 31 & 36 & 39 & 39 & 20 & 21 & 15 & 13 \\
\hline \multirow{2}{*}{$\mathrm{F} 2$} & 55 & 35 & 26 & 31 & 41 & 39 & 23 & 15 & 10 \\
\hline & $P=0.0007$ & NS & $P<0.00001$ & NS & NS & $P<0.00001$ & NS & NS & NS \\
\hline \multicolumn{10}{|l|}{ Marital status } \\
\hline Single & 36 & 55 & 32 & 24 & 32 & 25 & 26 & 20 & 18 \\
\hline Married & 58 & 34 & 38 & 43 & 29 & 32 & 13 & 13 & 11 \\
\hline \multirow[t]{2}{*}{ Widowed/separated } & 59 & 47 & 40 & 20 & 38 & 35 & 9 & 7 & 12 \\
\hline & $P<0.00001$ & $P<0.00001$ & NS & $P<0.00001$ & NS & NS & $P<0.00001$ & $P=0.00097$ & NS \\
\hline \multicolumn{10}{|l|}{ Employment status } \\
\hline Working & 49 & 45 & 36 & 32 & 31 & 27 & 20 & 16 & 17 \\
\hline Housewife & 66 & 31 & 43 & 46 & 28 & 37 & 0 & 9 & 10 \\
\hline Student & 27 & 66 & 28 & 33 & 31 & 17 & 33 & 21 & 10 \\
\hline Unemployed & 29 & 50 & 29 & 29 & 28 & 39 & 22 & 19 & 10 \\
\hline \multirow[t]{2}{*}{ Retired } & 53 & 33 & 34 & 23 & 43 & 29 & 21 & 14 & 13 \\
\hline & $P<0.00001$ & $P<0.00001$ & NS & $P=0.00016$ & NS & $P=0.00064$ & $P<0.00001$ & NS & NS \\
\hline \multicolumn{10}{|l|}{ Region } \\
\hline Dublin & 47 & 48 & 39 & 27 & 32 & 27 & 15 & 13 & 17 \\
\hline Rest of Leinster & 50 & 43 & 36 & 35 & 28 & 30 & 17 & 15 & 15 \\
\hline Munster & 50 & 45 & 29 & 40 & 34 & 27 & 21 & 12 & 12 \\
\hline \multirow{2}{*}{ Connaught/Ulster } & 56 & 31 & 41 & 32 & 29 & 38 & 15 & 23 & 10 \\
\hline & NS & $P=0.00208$ & NS & NS & NS & NS & NS & NS & NS \\
\hline \multicolumn{10}{|l|}{ Household size } \\
\hline 1 person & 55 & 42 & 42 & 4 & 56 & 31 & 2 & 12 & 26 \\
\hline 2 people & 54 & 33 & 36 & 35 & 30 & 33 & 18 & 18 & 12 \\
\hline 3 people & 53 & 43 & 39 & 37 & 31 & 25 & 19 & 13 & 10 \\
\hline 4 people & 48 & 47 & 31 & 40 & 32 & 29 & 19 & 17 & 14 \\
\hline \multirow[t]{2}{*}{$5+$ people } & 47 & 47 & 36 & 35 & 26 & 31 & 19 & 14 & 13 \\
\hline & NS & NS & NS & $P<0.00001$ & $P<0.00001$ & NS & NS & NS & NS \\
\hline
\end{tabular}




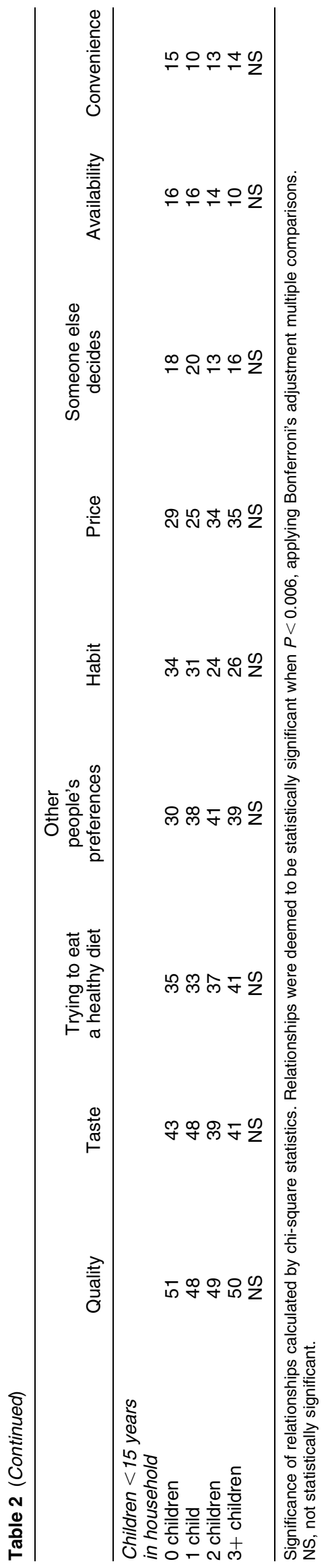

35 years, 32\% between 35 and 54 years and 25\% were 55 years or older. Twenty-six per cent of the subjects reported that that they had a primary level of education; 59\% had achieved secondary level and 15\% tertiary/ university level education. The social class breakdown was as follows: AB 9\%; C1 22\%; C2 20\%; DE 36\%; F1 6\% and $\mathrm{F} 2$ 7\%.

Table 1 shows the factors selected as the three most important influences on food choice by the total sample. 'Trying to eat a healthy diet' was selected by $13 \%$ of the sample as the most important factor affecting food choice. Overall, 'quality/freshness of food' was the most highly regarded attribute (selected by $51 \%$ of the sample), followed by 'taste' (43\%), 'trying to eat a healthy diet' (37\%) and 'other people's preferences' (34\%). Factors such as 'presentation/ packaging', 'slimming', 'vegetarian', 'prescribed diet', 'content of additives' and 'culture/religion' were regarded as important by less than $10 \%$ of the sample.

Table 2 shows the relationship between the subjects' sociodemographic characteristics and the selection of factors considered to be important influences on food choice. Applying the Bonferroni adjustment it was found that the belief that 'trying to eat a healthy diet' was an important consideration in food choice depended on sex (greater probability observed in females, $P<0.00001$ ), age (older, $P=0.00546$ ), education (higher levels of education, $P<0.00001$ ) and social class (higher level, $P<0.00001$ ). It must be borne in mind that once an option is selected, then the probabilities of selecting another option changes.

Sociodemographic variables were found to be highly interrelated. Thus, in order to determine the independent effects of sociodemographic characteristics on the belief that 'trying to eat a healthy diet' was an important influence on food choice, we conducted logistic regression analyses, which simultaneously controlled for the effects of the individual sociodemographics. In these logistic regression analyses, all other factors are corrected for. The group who did not select 'healthy eating' was the reference group. The results are presented in Table 3. It was found that males were significantly less likely than females to regard 'healthy eating' as an important influence on food choice (OR = 0.47; $P<0.00001)$. With decreasing age and level of education, there was a decreased probability that 'trying to eat a healthy diet' was regarded as important. Social class was also an independent determinant, with all classes except $\mathrm{C} 1$ significantly less likely than class $\mathrm{AB}$ to believe that 'trying to eat a healthy diet' was important. The main effect of region was only marginally significant, with none of the individual regions being statistically different to Dublin. In the final model there were no interactions between the main effects of sex, age, social class, region or education. 
Table 3 The probability of selecting 'healthy eating' as an important factor influencing food choice based on sociodemographic characteristics in a nationally representative sample of 1009 Irish adults - final logistic regression model

\begin{tabular}{|c|c|c|c|}
\hline & Odds ratio & $\begin{array}{l}95 \% \text { confidence } \\
\text { interval }\end{array}$ & $P$ \\
\hline $\begin{array}{l}\text { Sex } \\
\text { Male } \\
\text { Female }\end{array}$ & $\begin{array}{l}0.47 \\
1.00\end{array}$ & $0.35,0.61$ & $\begin{array}{l}<0.00001 \\
<0.00001\end{array}$ \\
\hline $\begin{array}{l}\text { Age (years) } \\
15-34 \\
35-54 \\
55+\end{array}$ & $\begin{array}{l}0.40 \\
0.65 \\
1.00\end{array}$ & $\begin{array}{l}0.27,0.55 \\
0.45,0.95\end{array}$ & $\begin{array}{c}<0.00001 \\
<0.00001 \\
0.0250\end{array}$ \\
\hline $\begin{array}{l}\text { Social class } \\
\text { F2 } \\
\text { F1 } \\
\text { DE } \\
\text { C2 } \\
\text { C1 } \\
\text { AB }\end{array}$ & $\begin{array}{l}0.28 \\
0.46 \\
0.41 \\
0.38 \\
0.60 \\
1.00\end{array}$ & $\begin{array}{l}0.13,0.59 \\
0.22,0.96 \\
0.23,0.71 \\
0.22,0.68 \\
0.39,0.94\end{array}$ & $\begin{array}{l}0.0056 \\
0.0009 \\
0.0385 \\
0.0015 \\
0.0011 \\
\text { NS }\end{array}$ \\
\hline $\begin{array}{l}\text { Region } \\
\text { Connaught/Ulster } \\
\text { Munster } \\
\text { Leinster } \\
\text { Dublin }\end{array}$ & $\begin{array}{l}1.32 \\
0.73 \\
1.04 \\
1.00\end{array}$ & $\begin{array}{l}0.86,2.01 \\
0.50,1.06 \\
0.70,1.53\end{array}$ & $\begin{array}{l}0.0404 \\
\text { NS } \\
\text { NS } \\
\text { NS }\end{array}$ \\
\hline $\begin{array}{l}\text { Education } \\
\text { Primary } \\
\text { Secondary } \\
\text { Tertiary }\end{array}$ & $\begin{array}{l}0.25 \\
0.47 \\
1.00\end{array}$ & $\begin{array}{l}0.15,0.43 \\
0.31,0.71\end{array}$ & $\begin{array}{c}<0.00001 \\
<0.00001 \\
0.0003\end{array}$ \\
\hline
\end{tabular}

\section{Discussion}

The main factors perceived by Irish adults to affect food choice are: quality/freshness, taste, healthy eating, other people's preferences and habit. Similar results were found among the other European populations included in the IEFS study, although subjects in some countries (e.g. Denmark) gave a higher priority to healthy eating than Irish adults ${ }^{8}$. In the USA the following order of factors affecting food choice has recently been reported: taste, cost, nutrition, convenience and weight concerns ${ }^{23}$. These differences between countries possibly highlight the fact that cultural differences play an important role in food choice $^{4}$.

The attribute 'quality/freshness' appears to be of considerable importance to almost all demographic groups. Of course the attribute 'quality' in terms of food could include aspects of health-giving properties, safety and taste, etc. A drawback of the present study is, however, that it gives no indication of what the term quality may mean to the consumers. Only males, subjects aged less than 35 years, singles, students, those from social class DE or unemployed regarded any other factor to be more important, namely taste. With regard to the latter two demographic groups, the perception that they cannot afford foods of good quality may be one of the reason that quality was not rated highly. In comparison with subjects in the other EU countries included in the survey, less Irish consumers selected 'quality/freshness' ${ }^{8}$.
The fact that healthy eating is included among the five most frequently mentioned factors could be regarded as encouraging to those involved in nutrition education, particularly when it is remembered that subjects were not prompted as to the substance of the survey. Subjects of female gender, greater age, educational level and socioeconomic status were the most likely to regard 'healthy eating' as an important influence on food choice. This finding is consistent with many surveys of both nutrition-related attitudes and behaviours of the general population. The food choices of females and of people of higher education, greater age and with greater levels of physical activity are frequently shown to be closest to dietary recommendations ${ }^{4,24}$. However, males and people with less education and of lower socioeconomic status may be more important target groups for nutrition education. This finding is consistent with those from other surveys ${ }^{25}$. Irish males with low levels of education were the least likely to regard healthy eating as an important factor influencing long-term good health? .

A greater level of regard for healthy eating was observed among subjects from Dublin and Connaught Ulster in the current survey, with a weak independent effect of region found on logistic regression analysis. The reasons for this are unclear, but this finding may represent an 'urbanization' effect, these being the regions in Ireland where the largest cities are found; however we did not include such a demographic factor in the survey.

One of the reasons that healthy eating was not given greater priority as a factor affecting food choice may be related to the general public's perceptions of their own diets. The IEFS survey has reported a low level of perceived need among Irish (and European) populations to alter their eating habits for health reasons, with the majority of the subjects surveyed believing that their diets are already adequately healthy ${ }^{13,14}$. Other studies have also demonstrated that people are falsely optimistic about the nutritional adequacy of their own diets. It was found that many people in the UK believed that they have reduced the fat content in their diets, although fat intake, as a percentage of energy, in the UK has remained stable for many years ${ }^{26}$. It is also reported that more than half of consumers with low fruit and vegetable intakes regard themselves as 'high consumers ${ }^{27}$. Another survey reported that $88 \%$ of consumers who, according to nutrition guidelines, did not eat enough vegetables rated themselves as adequate consumers, with a corresponding value of $65 \%$ for fruit ${ }^{28}$. If people believe that their diets are already healthy, whether or not they consciously strive for this, it may be unreasonable to expect them to alter their diets, or to consider nutrition/healthy eating as a highly important factor when it comes to choosing their 
food. Future nutrition intervention strategies should perhaps give emphasis to increasing awareness among the general population that their 'own' current dietary intakes are not wholly adequate in terms of, for example, fat or fruit and vegetable consumption.

The present survey also highlights differences between demographic groups in terms of the relative importance attached to some of the factors affecting food choice, e.g. taste. Further, a much greater percentage of men than women nominated 'habit' as an important influence on food choice. This is relevant in terms of nutrition education and the promotion of healthy eating to males, as it may partly explain why it can be more difficult to encourage men to change their eating patterns towards a healthy diet. More men than women also believed that 'someone else decides on most of the food I eat' as important. This would appear to demonstrate that men believe that their food intake is not completely under their own control, but may largely be the responsibility of a 'food gatekeeper', probably female, in the household. This, on first consideration, would appear to indicate, that in order to encourage dietary change among males, the persons responsible for food purchases and preparation would be a primary target group. However, research has shown that such gatekeepers' food choices and purchases are very largely influenced by food preferences of other people in the household ${ }^{29}$. This is also seen in the present survey, in that 'other people's preferences' was among the five most frequently mentioned factors influencing food choice.

Price was selected by $30 \%$ of the sample as an important factor affecting food choice, although this percentage rose to $40 \%$ among subjects classified in the lower socioeconomic groups or with lower levels of education. Cost has been reported as a barrier to dietary change in general ${ }^{16}$ and to increasing fruit and vegetable consumption in particular ${ }^{27}$. It has been shown that reducing the price of low-fat food items or of fruit and vegetables favourably affects food purchases ${ }^{30,31}$.

Differences in food preferences may partly explain the sociodemographic differences in factors affecting food choice observed in this study. Gender differences in food preferences have been reported ${ }^{32}$. In an Australian study on food preferences, foods which are generally considered as 'healthy' were found to be less popular among lower socioeconomic groups ${ }^{33}$. The latter finding may be due to reporting bias, different exposure to healthy foods among socioeconomic groups, the variable impact of healthy eating promotion campaigns across demographic groups, and economic barriers in the procurement of 'healthy foods ${ }^{33}$.

The present survey examines those factors perceived by consumers as having the greatest influence on their food choice, rather than the actual factors. In the study, less than $5 \%$ of the respondents reported that 'culture' played an important role in their food choice. It is well accepted that cultural differences play a major role in determining differences in food selection between countries $^{4}$, while it could be expected that 'culture' only plays a minimal role in countries with a relatively homogenous population like Ireland, at least in the eyes of the consumer. The deeply embedded role of culture in determining food choice is more likely to be perceived by the consumer as just day-to-day norms or 'habit' (see above).

Consumers may be more likely to act on what they perceive to be important rather than what may actually be so. Dietary changes are much more closely related to subjective than to objective dietary behaviour ${ }^{34}$. It has been shown in other studies that consumer's perceptions of what affects their food choice can predict food consumption. A positive relation has been found between the perception of nutrition as an important factor in food choice and fruit and vegetable consumption and a negative relation found between such a perception and eating in fast-food outlets ${ }^{23}$, showing that a greater concern about nutrition can predict whether a person eats more fruit and vegetables and less fast food.

People have many different eating occasions daily. The present study did not facilitate the measurement of motivations for food choice for different eating occasions. It is reasonable to expect that the motivations for eating at one particular occasion will differ from another eating occasion, for example habit may be a primary motivator for breakfast food choices, while taste and convenience may be much more important factors for foods eaten between main meals. Further research on the perceived influences on the different eating occasions would be useful for healthy eating promotion, particularly in the light of food-based dietary guidelines ${ }^{35}$. This could perhaps be accomplished using qualitative research techniques.

\section{Conclusions}

The main factors perceived to affect food choice by Irish consumers were quality, taste, healthy eating, other people's preferences and habit. Although healthy eating was included in the five most frequently mentioned influences it does not have top priority in the minds of most consumers. This may be related to an overoptimistic opinion of the nutritional adequacy of their diets found among Irish consumers ${ }^{13,14}$. The people most likely to regard healthy eating as important were females, subjects of older age, greater education and from higher social classes. By promoting foods on the basis of their other qualities (e.g. quality, taste, suitability for family), as well as on their health attributes, the promotion of healthy eating in Ireland may come to 
be perceived as more personally relevant to the general population. Given that there were some differences between the demographic groups, some people (e.g. male or younger subjects) may require additional specific messages, for example taste could be given greater emphasis in healthy eating messages to the younger target groups, while value for money could be stressed to lower socioeconomic groups.

\section{Acknowledgements}

The authors would like to acknowledge the assistance of the Project Management Group in conducting this survey.

\section{References}

1 Smith AM, Baghurst K, Owen N. Socio-economic status and personal characteristics as predictors of dietary change. $J$. Nutr. Educ. 1995; 27: 173-81.

2 Drenowski A. Taste preferences and food intake. Annu. Rev. Nutr. 1997; 17: 237-53.

3 Vaandrager HW, Koelen MA. Consumer involvement in nutritional issues: the role of information. Am. J. Clin. Nutr. 1997; 65: S1980-4.

4 Nestle M, Wing R, Birch L, et al. Behavioural and social influences on food choice. Nutr. Rev. 1998; 56: S50-64.

5 Harnack L, Block G, Lane S. Influence of selected environmental and personal factors on dietary behaviour for chronic disease prevention: a review of the literature. $J$. Nutr. Educ. 1997; 29: 306-12.

6 Johansson L. Nutrition education: the Norwegian experience. In: van der Heij DG, Lowik MRH, Ockhuizen Th, eds. Food and Nutrition Policy in Europe. Proceedings of the Second European Conference on Food and Nutrition Policy, The Hague, 21-24 April 1992. Wageningen: Puduc Scientific Publishers, 1993; 157-69.

7 Gibney MJ, Kearney M, Kearney JM. Introduction: IEFS panEU survey of consumer attitudes to food, nutrition and health. Eur. J. Clin. Nutr. 1997; 51: S2.

8 Lennernas M, Fjellstrom C, Becker W, et al. Influences on food choice perceived to be important by nationallyrepresentative samples of adults in the European Union. Eur. J. Clin. Nutr. 1997; 51: S8-15.

9 Kearney M, Kelly A, Gibney MJ. Attitudes towards and beliefs about nutrition and health among a nationallyrepresentative sample of Irish adults: application of logistic regression modelling. J. Nutr. Educ. 1998; 30: 139-48.

10 Kearney M, Kearney JM, Gibney MJ. Methods used to conduct the survey on consumer attitudes to food, nutrition and health on nationally-representative samples of adults from each member state of the European Union. Eur.J. Clin. Nutr. 1997; 51: S3-7.

11 Margetts BM, Martinez JA, Saba A, Moles A, Holm L, Kearney M. Definitions of 'healthy' eating: a pan-EU survey of consumer attitudes to food, nutrition and health. Eur.J. Clin. Nutr. 1997; 51: S23-9.

12 DeAlmeida MDV, Graca P, Lappalainen R, et al. Sources used and trusted by nationally-representative adults in the European Union for information on healthy eating. Eur. J. Clin. Nutr. 1997; 51: S16-22.

13 Kearney M, Gibney MJ, Martinez JA, et al. Perceived need to alter eating habits of adults from all member states of the European Union. Eur. J. Clin. Nutr. 1997; 51: S30-5.

14 DeGraaf C, VanderGaag $M$, Kafatos A, Lennernas M, Kearney JM. Stages of dietary change among nationallyrepresentative samples of adults in the European Union. Eur. J. Clin. Nutr. 1997; 51: S47-56.

15 Zunft HJF, Friebe D, Seppelt B, et al. Perceived benefits of healthy eating among a nationally-representative sample of adults in the European Union. Eur. J. Clin. Nutr. 1997; 51 S41-6.

16 Lappalainen R, Saba A, Moles A, Holm L, Mykkanen H, Gibney MJ. Difficulties in trying to eat healthier: descriptive analysis of perceived barriers for healthy eating. Eur. J. Clin. Nutr. 1997; 51: S36-40.

17 Market Research Society. Occupation Groupings. A Job Dictionary, 3rd edn. Bishop's Stortford, UK: Market Research Society, 1991.

18 ICC/ESOMAR. International Code of Marketing and Social Research Practice. Paris, Amsterdam: ICC/ESOMAR, 1995.

19 Barnett V. Sample Survey: Principles and Methods. London: Arnold, 1991

20 Kent R. Sampling cases. In: Kent R, ed. Marketing Research in Action. London: Routledge, 1993; 53.

21 Central Statistics Office. Census 1991. Vol. 1 Population. Dublin: Stationery Office, Government Publications, 1993.

22 Central Statistics Office. Census 1991. Vol. 2 Ages and Marital Status. Dublin: Stationery Office, Government Publications, 1993

23 Glanz K, Basil M, Maibach E, Goldberg J, Snyder D. Why Americans eat what they do: taste, nutrition, cost, convenience and weight control concerns as influences on food consumption. J. Am. Diet. Assoc. 1998; 98: 1118-26.

24 Hunt MK, Stoddard AM, Glanz K, et al. Measures of food choice behaviour related to intervention messages in worksite health promotion. J. Nutr. Educ. 1997; 29: 3-11.

25 Dittus KL, Hillers VN, Beerman KA. Benefits and barriers to fruit and vegetable intake - relationship between attitudes and consumption. J. Nutr. Educ. 1995; 27: 120-6.

26 Lloyd HM, Paisley CM, Mela DJ. Barriers to the adoption of reduced-fat diets in a UK population. J. Am. Diet. Assoc. 1995; 95: 316-22.

27 Cox DN, Anderson AS, Lean MEJ, Mela DJ. UK consumer attitudes, beliefs and barriers to increasing fruit and vegetable consumption. Public Health Nutr. 1998; 1: 61-8.

28 Lechner L, Brug J, DeVries H. Misconceptions of fruit and vegetable consumption: differences between objective and subjective estimation of intake. J. Nutr. Educ. 1997; 29: 31320.

29 Devine CM, Olson CM. Women's dietary prevention motives: life stage influences. J. Nutr. Educ. 1991; 23: 267-73.

30 Jeffrey RW, French RW, Raether C, Baxter JE. An environmental intervention to increase fruit and salad purchases in a cafeteria. Prev. Med. 1994; 23: 788-92.

31 French SA, Jeffrey RW, Story M, Hannan P, Snyder MP. A pricing strategy to promote low-fat snack choices through vending machines. Am. J. Public Health 1997; 87: 849-51.

32 Drenowski A, Holden Wiltse J. Taste responses and food preferences in obese women: effects of weight cycling. Int. J. Obes. 1992; 16: 639-48.

33 Turrell G. Socioeconomic differences in food preference and their influence on healthy food purchasing choices. $J$. Hum. Nutr. Diet. 1998; 11: 135-49.

34 Brug J, Lechner L, DeVries H. Psychosocial determinants of fruit and vegetable consumption. Appetite 1995; 25: 285-96.

35 FAO/WHO. Preparation and Use of Food-based Dietary Guidelines. Report of a Joint FAO/WHO Consultation. Geneva: World Health Organization, 1996. 